\title{
Structural and Impedance Enquiry on Biodegradable Blend Polymer Electrolytes of Cornstarch and Polyvinyl Pyrrolidone
}

\author{
M. Anandha Jothi, D. Vanitha, S. Asath Bahadur
}

\begin{abstract}
Biopolymer based Solid polymer blend electrolytes had been prepared utilizing Cornstarch (CS) and Poly vinyl pyrrolidone $(P V P)$ by the technique of solution casting. The readied electrolytes were described by XRD, FTIR and Impedance investigation. The structural properties of $C S$ and PVP blend Polymer Electrolytes (PEs) are dissected by XRD. The interaction among $P V P$ and $C S$ is considered by FTIR investigation. The electrical conductivity is calculated utilizing impedance analyser. The blend of $80 w t \%$ CS and $20 w t \% P V P$ is having the high conductivity $\left(4.90217 \times 10^{-9} \mathrm{~S} \mathrm{~cm}^{-1}\right)$ and low activation energy $(0.16 \mathrm{eV})$. The temperature dependent conductivity obeys the Arrhenius behaviour.
\end{abstract}

Keywords:Cornstarch, PVP, XRD, FTIR and Conductivity studies

\section{INTRODUCTION}

Solid polymer electrolytes (SPE) have impending application in electrochemical devices. It has simple fabrication, good electrode-electrolyte interface and biggest problem in electrochemical devices, such that leakage doesn't occur in SPE based system. Control of plastic waste is a worldwide problem in recent years. To overcome this issue, renewable and biodegradable material-based research is enormously increased. Bio polymers are best alternate for these types of synthetic polymers. Starch is a standout amongst the most prevalent renewable and biodegradable polymers to partially or completely supplant plastic polymer. Biopolymer starch is made out of glucose units and having two principle constituents are, amylase and amylopectin. Long chain of $\alpha-D$ glucose units connected together by $\alpha-1,4$ glycoside linkages are nearness in amylose and $\alpha-1,6$ linkages are interlinked with $\alpha-1,4$ linkages of glucose units in amylopectin [1].The overall measures of amylose and amylopectin rely on the plant source. Behind this, the selected biopolymer, cornstarch (CS) is having tiny particle size that offers enhanced dispersions in blends. CS is non-toxic, available in abundance, biodegradable and

Revised Manuscript Received on December 16, 2019

*Correspondence Author

M. Anandha Jothi, Department of Physics, IRC, Multi Functional material laboratory, Kalasalingam Academy of Research and Education, Krishnankoil, Tamil Nadu, India. Email: anandhajothi.m@klu.ac.in

D. Vanitha*, Department of Physics, IRC, Multi Functional material laboratory, Kalasalingam Academy of Research and Education, Krishnankoil, Tamil Nadu, India. Email:vanibala2003@gmail.com

S. Asath Bahadur, Department of Physics, IRC, Condensed Matter Laboratory, Kalasalingam Academy of Research and Education, Krishnankoil, Tamil Nadu, India. Email:s_a_bahadur@yahoo.co.in water soluble. $30 \%$ amylase and $70 \%$ amylopectin are present in CS granules [2]. The advancements of starchbased items are constrained by poor mechanical quality, high sensitivity to moisture, brittle, quickly degrades when exposed to water and its productive barrier against low polarity compound. In endeavors to beat this drawback, there have been numerous endeavors to join starch with synthetic polymers. By using artificial polymers which are biodegradable, starch-based polymer blends are prepared to use in the biomedical and natural fields. Biocompatible, biodegradable, nontoxic, extraordinary natural quality, effectively dissolvable in water and other polar solvents and amazing film-framing limit [3] as per these properties, Poly vinyl pyrrolidone (PVP) has gotten uncommon consideration than other conjugated polymers to blend with CS. Misleadingly PVP has been observed to be inert and it shows a sturdy affinity for a complex arrangement with a extensive collection of littler atoms [4]. Subject to electrical and optical properties of PVP is utilized for electrochemical devices, for example, energy storage devices with high limit. The present work principally examines the structure and ionic conductivity of CS-PVP mix biodegradable SPE. In this way it got incredible consideration and was widely researched.

\section{EXPERIMENTAL}

\section{A. Materials and Preparation method}

CS with a linear formula of $\mathrm{C}_{6} \mathrm{H}_{10} \mathrm{O}_{5}$ was purchased from SRL chemicals,Poly(vinyl pyrrolidone) with a linear formula of $\mathrm{C}_{6} \mathrm{H}_{9} \mathrm{NOwas}$ obtained from (S D Fine Chem Ltd., India). The biodegradable polymer blend electrolytes were prepared in different weight ratios of CS:PVP (100:0), (90:10), (80:20), (70:30), (60:40) and (50:50) by solution casting technique using DD water as solvent. The solution of CS was prepared in $50 \mathrm{ml}$ of $1 \%$ acetic acid and heated upto $75^{\circ} \mathrm{C}$ for 20 minutes. Various wt $\%$ of PVP were added to the solution after the solution attains the room temperature. Then the solutions were mixed and stirred for 24 hours until became homogenous and then transferred to Polypropylene Petri dishes. The solvent was permitted to evaporate gradually at room temperature. The prepared CS and PVP blend electrolytes were excluded from Petri dish for further analysis. All samples were stored airtight under room temperature. Table I shows the coding of different composition of the prepared polymer electrolytes. 


\section{Pyrrolidone}

Table -I: Sample code assignment of different composition ratio of CS:PVP

\begin{tabular}{|c|c|}
\hline Composition Ratio (CS:PVP) & Sample code \\
\hline $100: 0$ & VP-00 \\
$90: 10$ & VP-10 \\
$80: 20$ & VP-20 \\
$70: 30$ & VP-30 \\
$60: 40$ & VP-40 \\
$50: 50$ & VP-50 \\
\hline
\end{tabular}

\section{RESULTS AND DISCUSSION}

The preference of a proper extent of the polymer blend is its capability to act as a polymer host in electrolytes. The selection manages the crystallinity of the polymer blend. Two broad crystalline humps show up at $2 \theta=17^{\circ}, 19.8^{\circ}$, $21.9^{\circ}$, and $30.4^{\circ}[5,6]$ for the XRD of pure CS film $(100$ wt $\%$ starch). To diminish the crystallinity of CS, different wt\% of PVP is included. From the XRD, it is obviously detectable that the perceptible humps in the XRD become indistinct with increasing the PVP content. In the XRD pattern of the sample VP-20 is not having any distinct peak indicating the amorphous nature of the blend [7]. The advancement of a profoundly amorphous nature in this sample might be perceived as a key factor that acquires an enrichment of ions.

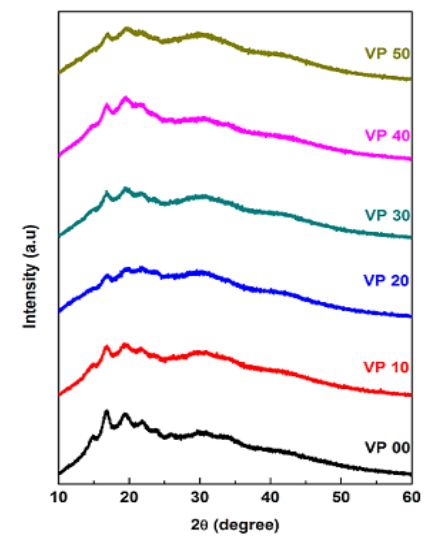

Fig. 1.X-ray diffractograms for different compositions of CS and PVP

The preference of a proper extent of the polymer blend is its capability to act as a polymer host in electrolytes. The selection manages the crystallinity of the polymer blend. Two broad crystalline humps show up at $2 \theta=17^{\circ}, 19.8^{\circ}$, $21.9^{\circ}$, and $30.4^{\circ}[5,6]$ for the XRD of pure CS film $(100$ wt\% starch). To diminish the crystallinity of CS, different wt\% of PVP is included. From the XRD, it is obviously detectable that the perceptible humps in the XRD become indistinct with increasing the PVP content. In the XRD pattern of the sample VP-20 is not having any distinct peak indicating the amorphous nature of the blend [7]. The advancement of a profoundly amorphous nature in this sample might be perceived as a key factor that acquires an enrichment of ions.

\section{B. FTIR Analysis}

FTIR is competent tool to study the local structural changes

\section{A. XRD Analysis}

in polymer. The infrared spectra of these materials differ according to their composition and assist in confirming the complex formation among polymer matrices. From FTIR spectra, the observed bands at 3285 and $2927 \mathrm{~cm}^{-1}$ are pertaining to the intermolecular hydrogen-bonded $\mathrm{O}-\mathrm{H}$ stretching and aliphatic stretchable $\mathrm{C}-\mathrm{H}$ mode of pure $\mathrm{CS}$ correspondingly. The band appeared at $1149 \mathrm{~cm}^{-1}, 995 \mathrm{~cm}^{-1}$ and $863 \mathrm{~cm}^{-1}$ which belongs to $\mathrm{C}-\mathrm{O}$ stretching, $\mathrm{C}-\mathrm{O}$ in $\mathrm{C}-$ $\mathrm{O}-\mathrm{C}$ groups and $\mathrm{C}-\mathrm{H}$ ring mode are mainly due to the starch and also used to monitor the starch content in the polymer blend. Some FTIR band assignment is exposed in Table II.

The intensity of the above said bands decreases by lowering the concentration of CS. The peak observed at $1006 \mathrm{~cm}^{-1}$ in the FTIR could be connected with $\mathrm{C}-\mathrm{O}-\mathrm{H}$ vibration [8]. It could be decreased by addition of PVP. The peak at 1,292 $\mathrm{cm}^{-1}$ is typical for $\mathrm{C}-\mathrm{N}$ bond in PVP was newly presented except VP-00 sample. The band at $1437 \mathrm{~cm}^{-1}$ is allocated to the stretchable $\mathrm{C}-\mathrm{N}$ vibrations and the addition of $\mathrm{CH}_{2}$ groups in the pyrrole ring of PVP [9, 10]. Jie-Jun Zhu et al reported the infrared transmission spectrum for pure PVP illustrates that the peak of the $\mathrm{C}=\mathrm{O}$ at $1660 \mathrm{~cm}^{-1}[11,12]$ was increased and vaguely moved to approximately $1647 \mathrm{~cm}^{-1}$ after blended with CS.

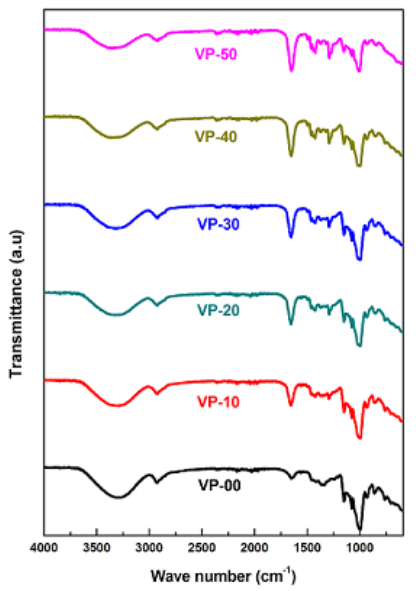

Fig. 2.FTIR for different compositions of CS and PVP

Table- II: FTIR assignment

\begin{tabular}{|c|c|}
\hline Wave number $\left(\mathbf{c m}^{-\mathbf{1}}\right)$ & Assignments \\
\hline 1651 & $\mathrm{C}=\mathrm{O}$ stretching of PVP \\
1437 & C-N stretching \\
1281 & C-H deformation \\
1149 & C-O stretching \\
995 & C-O in C-O-C groups \\
863 & C-H ring \\
\hline
\end{tabular}

\section{Impedance analysis}

Impedance spectroscopy gives a better perceptive in the conduction method and mobility processes. To calculate the ionic conductivity of electrolyte solutions, the following relationship is used:

$\sigma=l / \mathrm{R}_{\mathrm{b}} \mathrm{A}\left(\mathrm{S} \mathrm{cm}^{-1}\right)$

Where $\sigma$ is the conductivity of the sample in $\mathrm{S} \mathrm{cm}^{-1}$, the thickness of the polymer film is $l$ in $\mathrm{cm}$, the bulk resistance of the polymer film is $R_{b}$ in $\Omega$ and the area of the electrode/electrolyte is $\mathrm{A}$ in $\mathrm{cm}^{2}$.

\section{Published By:}

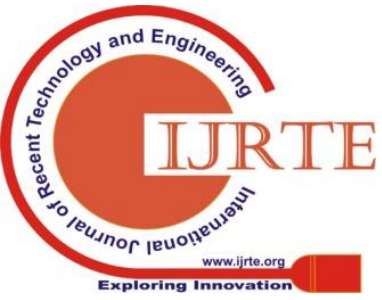


From fig. 3a, a semi-circle alone is observed for various composition of CS and PVP such as VP-00, VP-10, VP-20, VP-30, VP-40 and VP-50 blend polymer electrolytes .This semicircle is formed by the parallel combination of immobile charge (CPE - constant phase element) and mobile charge carrier (resistor) in polymer chain. The electrical comparable circuit symbol is usually utilized in impedance investigation since it is quick, straightforward and gives the entire representation of the framework [13]. $R_{b}$ value is measured from the intercept of the semicircle with the $\mathrm{X}$-axis at low frequency region. The conductivity has been increased up to VP-20 due to increase the amorphous nature (raise the wt\% of PVP) in PEs at ambient temperature. Above VP-20 conductivity has been decreased due to decrease the amorphous nature in PEs and increase in conductivity by Ion migration and exchange through this complexation sites. The conductivity of the different concentration of CS and PVP blend PEs at lowand at high temperatures are listed in table III. The higher conductivity obtained for VP-20 is $4.90217 \times 10^{-9} \mathrm{~S} \mathrm{~cm}^{-1}$ in the room temperature.

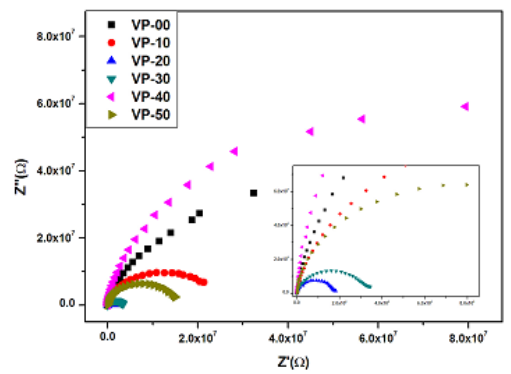

Fig. 3a. Nyquist plot for various compositions of CS and PVP

The fig. 3b shows the conductivity of the conductivity of the prepared films at various temperatures. From this, it is observed that the conductivity of the polymer electrolyte rises with temperature and spike is present due to the electrode and electrolyte interface effect. The conductivity of VP-20 polymer electrolyte increased to reach the value $1.15675 \times 10^{-8} \mathrm{~S} \mathrm{~cm}^{-1}$ at $358 \mathrm{~K}$.

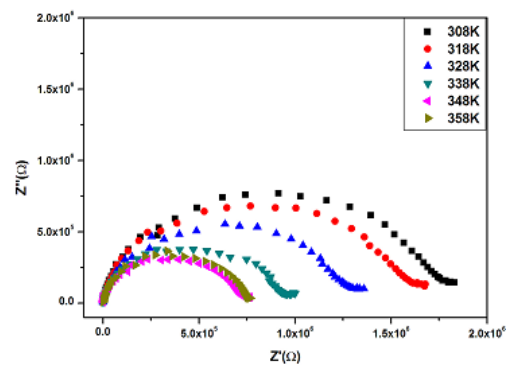

Fig. 3b. Nyquist plot for VP-20 at various temperatures

Table- III: Conductivity for all compositions of CS:PVP at low \& high temperature and Activation energy

\begin{tabular}{|c|c|c|c|}
\hline \multirow{2}{*}{$\begin{array}{l}\text { Sam } \\
\text { ple }\end{array}$} & \multicolumn{2}{|c|}{$\sigma\left(\mathrm{S} \mathrm{cm}^{-1}\right)$} & \multirow{2}{*}{$\begin{array}{l}E_{a} \\
(e V)\end{array}$} \\
\hline & $308 K$ & $358 K$ & \\
\hline VP-00 & $1.75999 \times 10^{-10}$ & $8.16905 \times 10^{-10}$ & 0.2 \\
\hline VP-10 & $3.53291 \times 10^{-10}$ & $1.50407 \times 10^{-9}$ & $\begin{array}{ll}8 & 0.2 \\
8 & \end{array}$ \\
\hline VP-20 & $4.90217 \times 10^{-9}$ & $1.15675 \times 10^{-8}$ & $6^{0.1}$ \\
\hline VP-30 & $3.1392 \times 10^{-9}$ & $8.40801 \times 10^{-9}$ & $9^{0.1}$ \\
\hline
\end{tabular}

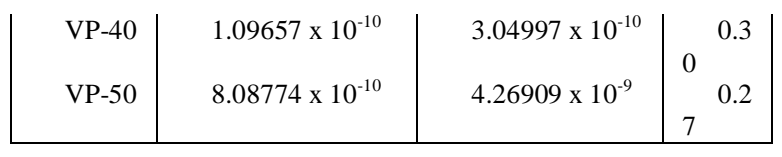

\section{Conductance spectra analysis}

In frequency dependence conductance spectra is helpful for know about the ion dynamics and conductance behavior in the SPEs at lower frequency to higher frequency and it is shown in fig. 4a. From frequency dependent conductance spectra, two regions are observed. There are lower frequency dispersion region and higher frequency dispersion region.

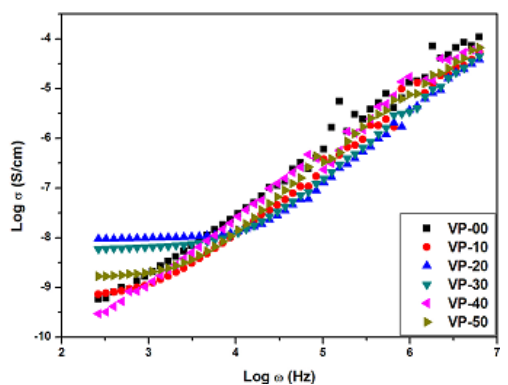

Fig. 4a. Conductance spectra for different concentrations of CS/PVP

At lower frequency dispersion region, the polarization effect shows the way to reduce the number of free ions and ultimately drop in conductivity at electrode interface with electrolyte and also space charge polarization. The higher conductivity in the high frequency region is due to the more prominent portability of charge carriers and quicker ion hopping.Along these lines, the ion exchange process happens all the more viably at higher frequencies. The extrapolations of low frequency plateau region to meet along $\mathrm{y}$-axis is used for determine the dc conductivity.

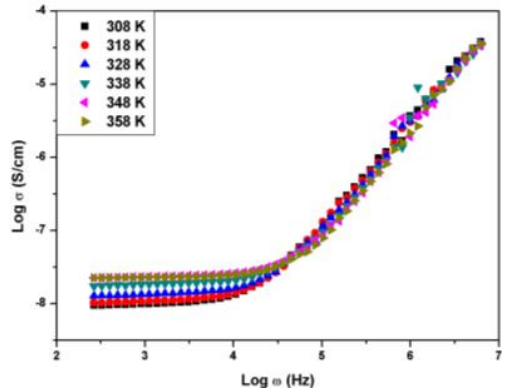

Fig. 4b. Conductance spectra for VP-20 at different temperature

From fig. 4a, VP-20 sample reaches high dc conductivity than other samples. At lower frequencies, the conductance spectra have variation due to the space charge polarization but there is no variations are observedin the higher frequency region. From $308 \mathrm{~K}$ to $358 \mathrm{~K}$, conductivity variations in high conducting sample observed particularly at low frequency as clearly shown in fig. $4 \mathrm{~b}$.

\section{E. Temperature dependent conductivity}

The temperature dependent conductivities of CS and PVP polymer blend electrolyte system investigated at temperature range of $313 \mathrm{~K}$ to $353 \mathrm{~K}$ as shown in fig. 5 . When the temperature increases the polymer matrices have been expended to form the free volume, then ions are easily migrated through the unoccupied spaces of the polymer matrices. In this way conductivity of ions in polymer electrolytes have

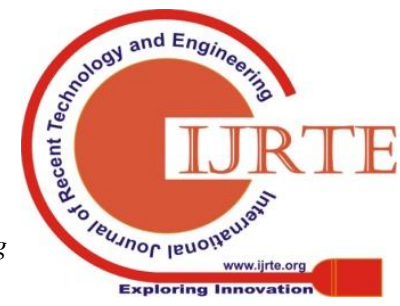


been enhanced with increasing temperatures according to ion hopping mechanism [14].

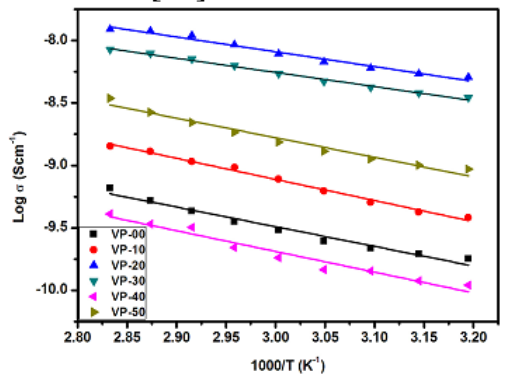

Fig. 5. Arrhenius plot for samples VP-00, VP-10, VP-20, VP-30, VP-40 and VP-50

Fig. 5 Draws between $\log \sigma$ and 1000/T graph. The conductivities are linearly increased by rising temperature in all the polymer electrolyte samples. All prepared samples to obey the Arrhenius behavior. Using linear fit, to find the slope of the straight line. The activation energy of the polymer electrolytes has been calculated with help of this slope value, using the following formula,

$\sigma(\mathrm{T})=\sigma_{\mathrm{o}} \exp \left(-\mathrm{E}_{\mathrm{a}} / \mathrm{KT}\right)$

Table III gives the observed conductivity and the activation energy values. The activation energy is found to be low $(0.16 \mathrm{eV})$ for the high conductivity sample VP-20 (80 wt. \% of CS +20 wt. \% of PVP).

\section{CONCLUSION}

Different compositions of CS and PVP blend polymer films have been prepared by solution cast technique. From the XRD results, 80 wt. $\%$ of CS +20 wt. \% of PVP was observed to be the most reasonable proportion because of the expansion in amorphous nature. The FTIR analysis reveals that the interchain hydrogen bonding between hydroxyl groups of CS and carbonyl groups of PVP. The higher conductivity at ambient temperature is found to be $4.90217 \times 10^{-9} \mathrm{Scm}^{-1}$ for the composition of VP-20. All the prepared electrolytes obeyed the Arrhenius rule. High conducting sample VP-20 has low activation energy of $0.16 \mathrm{eV}$.

\section{ACKNOWLEDGMENT}

Authors arethanked International Research centre (IRC), Kalasalingam Academy of Research and Education for Providing facilities and fellowships to carry out the research.

\section{REFERENCES}

1. M. Avella, J. D. J. Vlieger, M. A. Errico, S. Fischer, P. Vacca and M. G. Volpe, "Biodegradable starch/clay nanocomposite films for food packaging applications," Food Chem, vol. 93, pp. 467-474, December 2005.

2. J. F. Lambert and G. Poncelet, "Acidity in pillared clays: origin and catalytic manifestations," Topics in Catalysis, vol. 4, pp. 43-56, November 1997.

3. R. M. Hodge, G. H. Edward and G. P. Simon, "Water absorption and states of water in semicrystalline poly (vinyl alcohol) films," Polym, vol. 37, pp. 1371-1376, April 1996.

4. R. C. Agrawal and G. P. Pandey, "Experimental investigations on a proton conducting nanocomposite polymer electrolyte," J. Phys. D. Appl. Phys, vol. 41, pp. 055409, February 2008.

5. M. F. Shukur , R. Ithnin and M. F. Z. Kadir, "Electrical characterization of corn starch-LiOAc electrolytes and application in electrochemical double layer capacitor," J. Electrochimica Acta, vol. 136, pp. 204-216, August 2014.
6. R. V. Manek, P. F. Builders, W. M. Kolling, M. Emeje and O. O. Kunle, "Physicochemical and Binder Properties of Starch Obtained from Cyperus esculentus," J. AAPS. PharmSciTech, Vol. 13-2, June 2012.

7. Y. M. Yusof, M. F. Shukur, H. A. Illias and M. F. Z. Kadir, "Conductivity and electrical properties of corn starch-chitosan blend biopolymer electrolyte incorporated with ammonium iodide," Phys. Scr, vol. 89, pp. 035701, February 2014.

8. M. F. Shukur, F. M. Ibrahim, N. A. Majid, R. Ithnin and M. F. Z. Kadir, "Electrical analysis of amorphous corn starch-based polymer electrolyte membranes doped with LiI," J. Phys. Scr, vol. 88, pp. 025601 , July 2013.

9. T. Yong-Jin Han, M. A. Worsley, T. F. Baumann, J. H. Satcher, Jr, "Synthesis of $\mathrm{ZnO}$ coated activated carbon aerogel by simple sol-gel route,” J. Mater. Chem, vol. 21, pp. 330-333, November 2011.

10. M. Sudha and M. Rajarajan, "Deactivation of photocatalytically active $\mathrm{ZnO}$ nanoparticle by surface capping with poly vinyl pyrrolidone,’IOSR. J. Appl. Chem, vol. 3, pp. 45-53, February 2013.

11. Jie-Jun Zhu, Cai-Xia Kan, Jian-Guo Wan, Min Han, and Guang-Hou Wang, "High-yield synthesis of uniform Ag nanowires with high aspect ratios by introducing the long-chain PVP in an improved polyol process,” J. Nanomaterials, vol. 2011-40, pp.7, January 2011.

12. Vanitha Duraikkan, Sultan Asath Bahadur, Nallaperumal Nallamuthu, Shunmuganarayanan and Athimoolam, "Structural, thermal and electrical properties of polyvinyl alcohol/poly(vinyl pyrrolidone)sodium nitrate solid polymer blend electrolyte," J. Ionics, vol. 24, pp. 139-151, January 2018.

13. D. G. Han and G. M. Choi, "Computer simulation of the electrical conductivity of composites: the effect of geometrical arrangement," Solid State Ionics vol. 106, pp. 71-87, February 1998.

14. C. -W. Liew, S. Ramesh, K. Ramesh and A. K. Arof, "Preparation and characterization of lithium ion conducting ionic liquid-based biodegradable corn starch polymer electrolytes," J. Solid State Electrochem, vol. 16, pp. 1869-1875, May 2012.

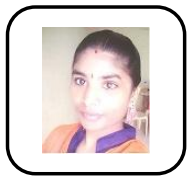

\section{AUTHORS PROFILE}

M. Anandha Jothi is a Research scholar in the department of Physics, International Research Centre (IRC), Kalasalingam Academy of Research and Education, India. She has received B.Sc., and M.Sc., degree in Physics from Madurai Kamaraj University. She is doing research in the area of Solid Polymer Electrolytes for Electrochemical application.

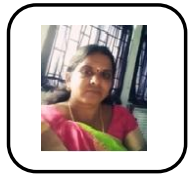

Dr. D.Vanitha is an Assistant Professor in the Department of Physics, School of Advanced Sciences at Kalasalingam Academy of Research and Education, India. She has obtained Ph.D. in the area of X-ray crystallography and Polymer Science from Kalasalingam Academy of Research and Education in 2016 and also received her M.Phil. and M.Sc. Degree in physics from Madurai Kamara University. She has expertise in the areas of Crystallography and Polymer Science. She has published more than ten peer-review research articles in journals of international repute besides ten more as proceedings.

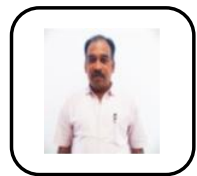

Dr. S. Asath Bahadur is a Senior Professor in the Department of Physics, School of Advanced Sciences at Kalasalingam Academy of Research and Education, India. He has obtained Ph.D. in the area of X-ray crystallography from Madurai Kamaraj University in 1994 and also received his M.Phil. and M.Sc. Degree in physics from Madurai Kamaraj University.He has expertise in the areas of Crystallography and Material science. He has published more than eightyfivepeer-review research articles in journals of international repute besides seventy more as proceedings. 